\title{
Mini direct cholangioscopy and direct targeted bile duct biopsies using a laser fiber through a biliary catheter
}

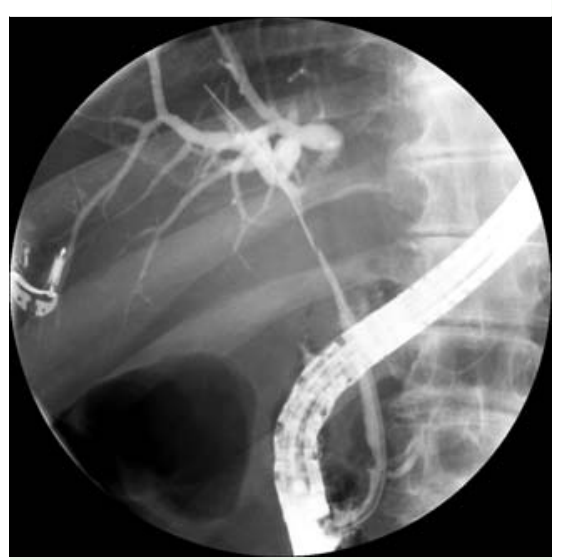

Fig. 1 Cholangiogram showing a tight stricture at the level of the common hepatic duct, Bismuth type I.

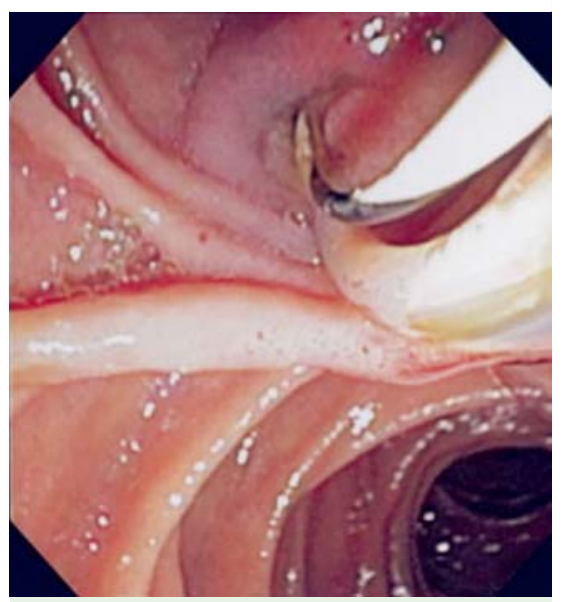

Fig. 2 The catheter loaded with the laser fiber ("mini-cholangioscope") has been advanced into the common bile duct along a guide wire.

Cholangioscopy has improved our ability to study diseases of the biliary tract and to provide therapy $[1,2]$. A prerequisite for cholangioscopy using available systems is the presence of common bile duct dilation and a previous sphincterotomy $[1,2]$. We present a modified technique for performing cholangioscopy in patients with a stenosed common bile duct and/or intact papilla.

A 77-year-old man with coronary artery disease, diabetes mellitus, hypertension, and arthritis presented with jaundice due a common bile duct stricture. On clinical examination he appeared well. The liver

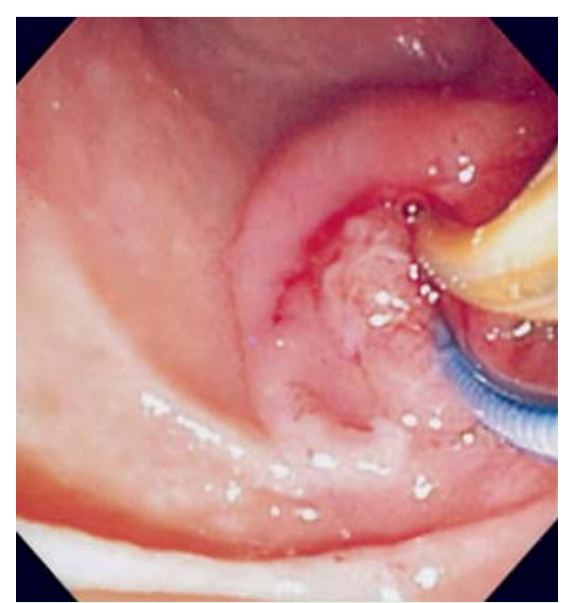

Fig. 3 Biopsy forceps introduced beside the "mini-cholangioscope".

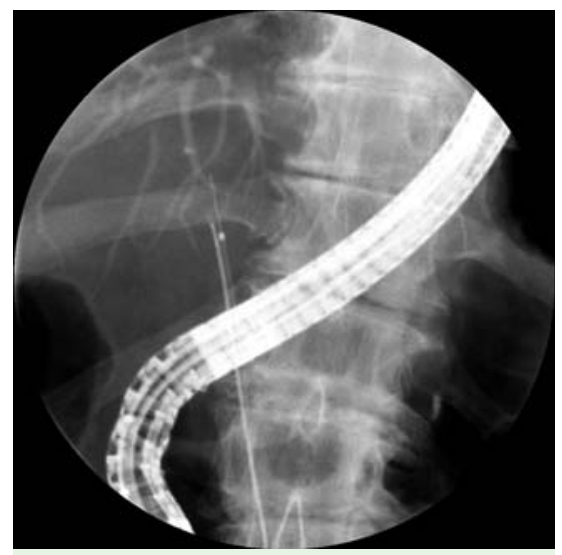

Fig. 4 Fluoroscopic image of the opened biopsy forceps alongside the tip of the "minicholangioscope" inside the biliary stricture.

tests were abnormal, showing elevated bilirubin $(4.7 \mathrm{mg} / \mathrm{dL}$, normal $0.5-1.2)$, alkaline phosphatase (212 IU/L, normal < 125), and hypoalbuminemia $(2.9 \mathrm{~g} / \mathrm{L}$, normal $3.5-4.5)$. The remaining laboratory results were within reference ranges. CT of the abdomen showed a thickening of the bile duct. Linear array echoendoscopic examination did not reveal any mass lesions in the pancreatic head or the bile duct. Fineneedle aspiration of the thickened common hepatic duct was performed and rapid on-site cytopathological analysis showed benign ductal cells with no evidence of malignancy. Endoscopic retro- grade cholangiopancreatography disclosed a 3-cm-long stricture of the common hepatic duct with dilation of the intrahepatic ducts ( Fig. 1). Because the distal common bile duct was thin and not dilated, insertion of the Spyglass or an ultrathin gastroscope to perform direct cholangioscopy proved impossible. Thus it was decided to place the laser fiber of the SpyGlass directly into the bile duct using a standard 5-Fr biliary catheter (Tandem XL; Boston Scientific, Natick, Massachusetts, USA) as its "guide tube". The biliary catheter was advanced along a previously placed guide wire ( $\bullet$ Fig. 2 ). In this way a mini direct cholangioscopy was performed ( Video 1). At the level of the biliary stricture, irregular mucosa and neovascularization were noted. The guide wire was then removed and the 1.2-mm-diameter Spybite forceps (Boston Scientific) advanced along the mini-cholangioscope ( $\bullet$ Fig.3). In this way directed biopsies were successfully obtained ( Video 2 , - Fig.4). Histology revealed an adenocarcinoma. The patient is to undergo surgical resection.

This case is interesting for several reasons. First, we demonstrate that mini-cholangioscopy is feasible. We show that the main issue in cholangioscopy is to provide a centered luminal view for the fiber to explore the bile duct. This 6000-pixel fiberoptic probe allows a $70^{\circ}$ field of view, providing adequate luminal visualization regardless of whether it is inside a thick "cholangioscope" or a thin catheter. Second, we showed that directed biopsies also are also possible using this modified cholangioscopy technique. And third, the papilla was not incised, showing that cholangioscopy can be performed through an intact papilla. Furthermore, with an intact papilla there is less influx of air into the bile duct, with adequate retention of normal saline, giving better visualization. Care should be taken not to pump in too much water into the bile duct. Sphincterotomy is not always mandatory before

\section{Video 1}

Cholangioscopic view of the nodular, ulcerating, protruding common hepatic duct mass (cholangiocarcinoma).

\section{Video 2}

Cholangioscopy-directed biopsies using the Spyglass "mini-cholangioscope." 
the insertion of metal or plastic stents and is contraindicated in anticoagulated patients or those with coagulopathies. Thus, our method is also of potential use in these kinds of patients.

Endoscopy_UCTN_Code_TTT_1AR_2AD

Competing interests: None

\section{J. Ramesh, C. M. Wilcox, K. Mönkemüller}

Division of Gastroenterology and Hepatology, Basil Hirschowitz Endoscopic Center of Excellence, University of Alabama at Birmingham, Alabama, USA

\section{References}

1 Pohl J, Ell C. Direct transnasal cholangioscopy with ultraslim endoscopes: a one-step intraductal balloon-guided approach. Gastrointest Endosc 2011; 74: 309-316

2 Williamson JB, Draganov PV. The usefulness of SpyGlass ${ }^{\mathrm{TM}}$ choledochoscopy in the diagnosis and treatment of biliary disorders. Curr Gastroenterol Rep 2012; 14: 534-541
Bibliography

Dol http://dx.doi.org/

10.1055/s-0032-1326373

Endoscopy 2013; 45: E127-E128

(c) Georg Thieme Verlag KG

Stuttgart · New York

ISSN 0013-726X

\section{Corresponding author}

\section{K. Mönkemüller, MD, PhD}

Division of Gastroenterology and Hepatology University of Alabama at Birmingham 6th Floor Jefferson Tower

625 19th Street South Birmingham, AL 35249 USA

Fax: +1-205-934-1537

moenkemueller@yahoo.com 